American J. of Engineering and Applied Sciences 4 (3): 400-404, 2011

ISSN 1941-7020

(C) 2014 G.S. Kumaran et al., This open access article is distributed under a Creative Commons Attribution

(CC-BY) 3.0 license

\title{
Analysis of the Transport Properties of Tyre Fiber Modified Concrete
}

\author{
${ }^{1}$ Senthil Kumaran, G., ${ }^{2}$ M. Lakshmipathy and ${ }^{1}$ Nurdin Mushule \\ ${ }^{1}$ Department of Civil Engineering and Environmental Technology, \\ Faculty of Engineering, Kigali Institute of Science and Technology, \\ BP3900, Kigali, Rwanda \\ ${ }^{2}$ Department of Civil Engineering, Faculty of Engineering and Technology, \\ SRM University, Chennai, Tamilnadu, India
}

\begin{abstract}
Problem statement: Nowadays, the use of waste tyre in concrete has become technically feasible and the tyre mixed concrete is light weight and called as rubberized concrete. Still the research is going on to explore basic engineering properties such as transport properties viz, acid absorption test, water absorption tests, impact resistance, modulus of elasticity, dynamic modulus and so on. In this study, the studies are limited to acid absorption test, water absorption test and energy absorbed by impact. Approach: Experimental investigations were conducted on tyre fiber specimens with different variables such as length, diameter of holes and percentage of coarse aggregate replacement by tyre fibers. Impact resistance test was done by ACI standard and acid and water absorptions tests were conducted by Indian standard. Results: In this study, experimental results based on the water absorption, acid resistance and impact resistance of the rubberized concrete were analyzed. These experiments were conducted on rubberized concrete with tyre fibers mixed in different sizes and proportions by weight with the coarse aggregate. The specimens were immersed in water and in diluted HCL (5\% concentration) acid for 28 days and tested. Conclusion: The results obtained from the tests are use to determine the optimum size of the tyre fiber specimen that could be used in the rubberized concrete mixture to give the optimum performance. The rubberized concrete with tyre fiber specimen L50-D5 10\% has shown good transport characteristics and impact resistance.
\end{abstract}

Key words: Tire fiber, water absorption, acid resistance, compression strength, impact resistance give, concrete mixed, fiber specimen

\section{INTRODUCTION}

The increasing piles of used tyres at landfill sites presents threat of uncontrolled fires, producing a complex mixture of chemicals harming the environment and contaminating soil and vegetation. It is estimated that in UK alone 37 million car and truck tyres are being discarded annually and this number is set to increase. This is considered as one of the major environmental challenge that the world is facing because waste rubber is not easily biodegradable even after a long period of landfill treatment. One of the solutions suggested is the use of tyre rubber as a partial replacement of coarse aggregate in the cement-based materials proposed by Dhir et al. (2001). Although concrete is the most popular construction material, it has some limitation in properties like low tensile strength, low ductility, low energy absorption and shrinkage and cracking associated with hardening and curing (Wang et al., 2000). Several studies performed recently have shown that the application of the recycled tyre rubber in the concrete would improve the weak characteristics of the concrete.

Rubberized concrete: The concrete mixed with waste rubber added in different volume proportions is called as Rubberized concrete and is an infant technology. Partially replacing the coarse aggregate of the concrete with some quantity of waste tyre cubes could give qualities such as low unit weight, high resistance to abrasion, absorption to shocks and vibrations, high ductility and brittleness to the concrete. Moreover the inclusion of rubber into concrete results in higher resilience, durability and elasticity (Lee et al., 1993; Eldin and Senouci, 1993a; Toutanji, 1996; Raghavan et al., 1998; Li et al., 1998; Bignozzi et al., 2000; Raghavan, 2000; Senthilkumaran et al., 2008). The literature reveals that the tests conducted by Eldin and Senouci (1993b) on concrete with tire chips and crumb

Corresponding Author: Senthil Kumaran, G., Department of Civil Engineering and Environmental Technology, KIST, BP3900, Kigali, Rwanda 
rubber of sizes 19, 25 and $38 \mathrm{~mm}$ considerably reduces the compressive strength and split tensile strengths but can withstand to absorb large amount of plastic energy. Biel and Lee (1994) has proven that magnesium chloride cement gives good bonding strength and the rubber content should be limited to $17 \%$. Schimizze et al. (1994) mentioned that reduction in elastic modulus with higher flexibility is suitable for stabilized base for flexible pavements. Topcu (1995) investigated the effect of particle size and content of tire rubbers and found the strength was reduced considerably and the plastic capacity was enhanced. Serge and Joekes (2000) used saturated $\mathrm{NaOH}$ solution to treat waste tire rubber to make good interfacial bonding strength. Zheng et al. (2008) mentioned in their study that there was considerable reduction in compressive strength, static modulus of elasticity and the dynamic modulus of elasticity with the increasing amount of rubber content. From the literature reviews it is seen that none of the researchers have done any research on the water absorption, acid resistance and impact resistance properties of tyre fiber modified concrete.

Experimental program: The main objective of this research is to determine the inherent transport properties of the tyre fiber modified concrete such as water absorption and acid resistance. The impact resistance is also tested. The tests were conducted on composites formed with tyre fibers with lengths $25 \mathrm{~mm}$, $50 \mathrm{~mm}, 75 \mathrm{~mm}$ and different diameter of holes $4 \mathrm{~mm}$, $5 \mathrm{~mm}$ and $6 \mathrm{~mm}$ designated as L25-D4, L25-D5, L25D6; L50-D4, L50-D5, L50-D6; and L75-D4, L75-D5, L75-D6. These tyre fibers were used to partially replace $0,5,10,15,20$ and $25 \%$ of the coarse aggregate by total weight to cast different composites with varying $\%$ of tyre fiber mixes as proposed by Senthilkumaran et al. (2008). The water and acid absorption were measured at the age 28days of all concretes. Impact Resistance tests were also conducted on the samples.

\section{MATERIALS AND MATHODS}

The locally available materials were used for this study. Fly ash based Grade 53 cement, Fine River sand, coarse aggregate of sizes $20(60 \%)$ and $10 \mathrm{~mm}(40 \%)$ and tyre fibers. All the tyre fibres were cleansed by using analytical grade NAOH (Eldin and Senouci, 1993a) to remove grease and other impurities in rubber in order to improve adhesion with the cement matrix. All the materials were confirmed to the Bureau of
Indian standard for the mix design of concrete. Tyre fibers of different length and diameters were used in the partial replacement of the coarse aggregate. The fine aggregate was sieved using $2.36 \mathrm{~mm}$ in order to pass through the holes of the tyre fiber to make a strong contact with cement matrix. Water with neutral $\mathrm{pH}$ value has been used for mixing. All these study were done under room temperature.

Mixture design: Mix was designated as a concrete of $40 \mathrm{MPa}$ with a mix ratio of 1:1:2.5 using Indian Standard of Concrete Mix Design. The water-cement ratio was designed as 0.40 . To prepare rubberized concrete mixture, all the parameters are kept constant except tyre fibers were used to replace a $\%$ of the coarse aggregate by its weight. Nine different types tyre fibers with lengths $25,50,75 \mathrm{~mm}$ and different hole diameters 4-6mm designated as L25-D4, L25-D5, L25D6; L50-D4, L50-D5, L50-D6; and L75-D4, L75-D5, L75-D6 were used. These tyre fibers were partially replaced $0-5 \%, 10-15-20$ and $25 \%$ by weight of the coarse aggregate of size $20(60 \%)$ and $10 \mathrm{~mm}(40 \%)$.

Using the above tyre fibers, 45 different mixtures were produced with a control specimen of $0 \%$ rubber. $150 \times 150 \times 150 \mathrm{~mm}$ moulds were used to prepare cubes for compressive strength tests and $150 \mathrm{~mm}$ diameter and $300 \mathrm{~mm}$ length cylindrical specimens were used for split tensile tests. Each specimen were cast and compacted by a vibrating table. For this study a total of 270 cubes, 10 small cylindrical specimen for Impact Resistance Test and 270 cylinders were cast. All the specimens were cast in the room temperature and remolded after $24 \mathrm{~h}$. and immersed in curing tank for curing. All the tests were conducted as per Indian Standards and the Impact Resistance test was based on ACI method. In all the cubes and cylinders the tyre fibers were having varying number of holes and were randomly distributed.

Acid resistance test: All the specimens were immersed in $5 \%$ diluted HCL acid for 28days. After 28 days the weight of the specimens were measured to calculate the percentage of acid penetration. The percentage of absorption were calculated by the difference in weight of concrete cubes, before and after immersed in the acid. Table 1 shows the average $\%$ of acid absorption of the specimens.

It is observed that the \% of acid absorption is generally lower in almost all cases when compared with the control specimen as seen in the Table 1 . But in some cases especially with L75-D6 25\% fiber mix the absorption is higher. 
Am. J. Engg. \& Applied Sci., 4 (3): 400-404, 2011

Table 1: Average \% of acid absorption

Cubes-Acid absorption test

Average (\%) of acid absorption

\begin{tabular}{llllll} 
Specimen ID & $5 \%$ & $10 \%$ & $15 \%$ & $20 \%$ & $25 \%$ \\
\hline L25 D4 & 0.21 & 0.03 & 0.17 & 0.07 & 0.26 \\
L25 D5 & 0.10 & 0.23 & 0.33 & 0.45 & 0.58 \\
L25 D6 & 0.14 & 0.27 & 0.30 & 0.47 & 0.53 \\
L50 D4 & 0.28 & 0.35 & 0.39 & 0.14 & 0.64 \\
L50 D5 & 0.12 & 0.33 & 0.38 & 0.50 & 0.59 \\
L50 D6 & 0.18 & 0.37 & 0.42 & 0.55 & 0.66 \\
L75 D4 & 0.51 & 0.49 & 0.49 & 0.40 & 0.93 \\
L75 D5 & 0.27 & 0.68 & 0.54 & 0.73 & 0.93 \\
L75 D6 & 0.28 & 0.47 & 0.62 & 0.74 & 0.89 \\
Control & & & & & \\
Specimen & 0.56 & & & & \\
\hline
\end{tabular}

Table 2: Average $\%$ of water absorption

\begin{tabular}{lllllr}
\hline & \multicolumn{2}{l}{$\begin{array}{l}\text { Cubes-Water absorption test } \\
\text { Average }(\%) \text { of water absorption }\end{array}$} \\
& ---------------- & \\
Specimen ID & $5 \%$ & $10 \%$ & $15 \%$ & $20 \%$ & $25 \%$ \\
\hline L25 D4 & 1.88 & 2.63 & 5.37 & 6.47 & 5.53 \\
L25 D5 & 2.27 & 2.84 & 4.95 & 5.11 & 5.75 \\
L25 D6 & 1.88 & 2.63 & 3.41 & 5.53 & 6.78 \\
L50 D4 & 2.59 & 3.12 & 3.84 & 4.76 & 6.78 \\
L50 D5 & 2.48 & 2.63 & 3.03 & 5.26 & 7.11 \\
L50 D6 & 1.64 & 1.87 & 3.42 & 3.79 & 6.45 \\
L75 D4 & 2.78 & 4.89 & 5.25 & 5.53 & 10.39 \\
L75 D5 & 2.86 & 3.43 & 4.59 & 6.90 & 8.23 \\
L75 D6 & 1.50 & 2.69 & 4.08 & 4.97 & 9.49 \\
Control & & & & & \\
Specimen & 3.88 & & & & \\
\hline
\end{tabular}

This due to the fact that longer dimension of the tyre fiber may not mix evenly with the cement aggregate and can create voids in the composite. This will increase the acid absorption. This fact can be justified by seeing the $\%$ of acid absorption in the rubberized concrete with L25 dimension fibers. It is noted that there is significant decrease in the $\%$ of acid absorption from $5-25 \%$ mix. This is because smaller length fibers are more evenly distributed and get mixed with the cement aggregate without creating many pores. L50 mix shows lower \% of acid absorption when compared to the control specimen but slightly higher than the L25 mix.

Water absorption test: All the specimens were immersed in $\mathrm{pH}$ neutral water under shade for 28days. After 28 days the weight was measured to calculate the percentage of water absorption. The weights of the cubes were taken before after immersion of water in order to calculate the percentage of water absorption by the tyre fiber mixed concrete. This test is done to determine absorption nature of concrete with varying \% of rubber fibers. Table 2 shows the average $\%$ of water absorption of the specimens.
Table 3: Effect of acid absorption on compressive strength Cubes-Compression test Average compressive strength $\left(\mathrm{N} \mathrm{mm}^{-2}\right)$

\begin{tabular}{llllll} 
& - & - & & & \\
Specimen ID & $5 \%$ & $10 \%$ & $15 \%$ & $20 \%$ & $25 \%$ \\
\hline L25 D4 & 26.30 & 21.51 & 20.78 & 14.39 & 16.42 \\
L25 D5 & 24.85 & 17.59 & 24.12 & 15.40 & 11.19 \\
L25 D6 & 29.65 & 30.96 & 28.34 & 16.42 & 22.53 \\
L50 D4 & 26.30 & 25.00 & 20.64 & 17.15 & 12.06 \\
L50 D5 & 26.30 & 29.36 & 12.02 & 12.79 & 12.64 \\
L50 D6 & 22.38 & 19.62 & 17.44 & 18.02 & 15.26 \\
L75 D4 & 20.49 & 23.40 & 16.00 & 15.26 & 9.74 \\
L75 D5 & 19.48 & 16.70 & 14.10 & 9.16 & 6.40 \\
L75 D6 & 23.98 & 19.90 & 13.22 & 11.77 & 4.65 \\
Control & & & & & \\
Specimen & 33.86 & & & & \\
\hline
\end{tabular}

From Table 2 it is observed that up to $15 \%$ of tyre fiber mixed rubberized concrete the $\%$ of water absorption is low when compared to the control specimen. But beyond $15 \%$ of rubber mix the $\%$ of water absorption increases abruptly. This clearly explains the fact that up to $15 \%$ of inclusion of rubber fibers the blockage of the pores by the tyre fibers outnumbers the voids created by them, so the overall absorption is low. But, if the \% of mix increases, the voids created are more and hence the absorption is high. This shows that for a durable rubberized concrete the mix proportion of tyre fibers should not exceed $15 \%$.

Also it is interesting to note that L50 tyre fiber mixed concrete has shown good reduction in water absorption when compared to L25 and L75 tyre fibers. The simple drop weight was used to find out the Impact Resistance of the control specimen and tyre fiber modified concrete specimens after 28days. A standard steel ball of $4.5 \mathrm{~kg}$ weight was used to make impact on the concrete specimens, dropping from $50 \mathrm{~cm}$. The drop hammer was placed over the steel ball. The base plate has to bolt to the rigid concrete floor base. A counter was used to count the number of blows. The hammer was dropped repeatedly and the number of blows was counted till the development of first crack and the ultimate crack. Ultimate crack means the opening of crack completely in the specimen and the pieces of concrete are touching three of the lugs on the base plate.

\section{RESULTS}

Effect of acid absorption on compressive strength: Compression test was conducted on the 28th day age of acid absorbed rubberized concrete cubes. The results are shown in Table 3.

Impact resistance test: The Impact resistance was done on specimens with tyre fibers L50 and L75 lengths with different percentage of tyre fibres. The specimens and the tests were done based on the procedure described by ACI. The specimen is of size $150 \mathrm{~mm}$ diameter and $62.5 \mathrm{~mm}$ height. 
Am. J. Engg. \& Applied Sci., 4 (3): 400-404, 2011

Table: 4 Effect of water absorption on compressive strength Cubes-Compression test

Average compressive strength $\left(\mathrm{N} \mathrm{mm}^{-2}\right)$

\begin{tabular}{|c|c|c|c|c|c|}
\hline \multirow[b]{2}{*}{ Specimen ID } & \multicolumn{5}{|c|}{$\begin{array}{l}\text { Cubes-Compression test } \\
\text { Average compressive strength }\left(\mathrm{N} \mathrm{mm}^{-2}\right)\end{array}$} \\
\hline & $5 \%$ & $10 \%$ & $15 \%$ & $20 \%$ & $25 \%$ \\
\hline L25 D4 & 37.24 & 22.50 & 17.00 & 16.65 & 8.42 \\
\hline L25 D5 & 27.32 & 28.73 & 23.26 & 18.43 & 9.57 \\
\hline L25 D6 & 28.77 & 26.39 & 17.84 & 17.12 & 11.98 \\
\hline L50 D4 & 27.61 & 23.20 & 25.53 & 22.20 & 10.27 \\
\hline L50 D5 & 24.23 & 30.90 & 18.72 & 16.94 & 14.97 \\
\hline L50 D6 & 22.05 & 26.74 & 19.27 & 12.64 & 18.31 \\
\hline L75 D4 & 33.72 & 25.10 & 26.27 & 14.37 & 15.10 \\
\hline L75 D5 & 34.14 & 26.30 & 19.85 & 19.62 & 13.20 \\
\hline L75 D6 & 21.73 & 22.80 & 21.03 & 8.70 & 9.43 \\
\hline \multicolumn{6}{|l|}{ Control } \\
\hline Specimen & 41.87 & & & & \\
\hline
\end{tabular}

Table 5: Impact resistance of control specimen

\begin{tabular}{lll}
\hline & Energy Absorbed (Joules) in \\
\hline Specimen ID & Initial crack & Final crack \\
\hline Control specimen & $3290.4 \mathrm{~J}$ & $3907.3 \mathrm{~J}$ \\
\hline
\end{tabular}

Table 6: Impact resistance of rubberized concrete

\begin{tabular}{|c|c|c|}
\hline \multirow[b]{2}{*}{ Specimen ID (\%) } & \multicolumn{2}{|c|}{ Energy Absorbed (Joules) in } \\
\hline & Initial crack & Final crack \\
\hline L50-5 & $3187.6 \mathrm{~J}$ & $5881.6 \mathrm{~J}$ \\
\hline L50-10 & $3598.9 \mathrm{~J}$ & $5758.2 \mathrm{~J}$ \\
\hline L50-15 & $3249.3 \mathrm{~J}$ & $5573.2 \mathrm{~J}$ \\
\hline L50-20 & $2940.8 J$ & $4730.0 \mathrm{~J}$ \\
\hline L50-25 & $3146.4 \mathrm{~J}$ & $4318.7 \mathrm{~J}$ \\
\hline L75-5 & $1336.7 \mathrm{~J}$ & $3023.1 \mathrm{~J}$ \\
\hline L75-10 & $2056.5 \mathrm{~J}$ & $2262.2 \mathrm{~J}$ \\
\hline L75-15 & $3290.4 \mathrm{~J}$ & $4071.9 \mathrm{~J}$ \\
\hline L75-20 & $3640.0 \mathrm{~J}$ & $4503.7 \mathrm{~J}$ \\
\hline L75-25 & $4318.7 \mathrm{~J}$ & $5038.4 \mathrm{~J}$ \\
\hline
\end{tabular}

Effect of water absorption on compressive strength: The compressive tests were done at the age of 28 days. Then the cubes were crushed after 28days to determine its compressive strength and the results were compared with the control specimen. The results are shown in Table 4.

Impact resistance test: Using the above procedure the impact resistance of the control concrete without tyre fibers and other tyre fibber modified concrete with different $\%$ of mix has been measured and given in Table 5 and 6.

\section{DISCUSSION}

Observed from the Table 3, the compressive strength of Acid Resistance (Absorption) cubes was decreasing gradually with gradual increase of $\%$ of tyre fibres in concrete. Here also, it was noted that L50D5$10 \%$ performed better than L50D6-10\%. The percentage of reduction of compressive strength for L50D5-10\% was $12.58 \%$ and for L50D6-10\% was $42 \%$ when compare with control specimen. This may due to the chemical reaction between the matrix and the HCL acid. The number of holes may also contribute the reduction in the strength.

It is observed from the table that the compressive strength of Water Absorbed cubes has reduced moderately up to $15 \%$ mix and high beyond that.

Generally L50 mix performed better compared to other samples and in particular L50-D5-10\% performed better than L50D6-10\%. The percentage of reduction of compressive strength for L50D5-10\% was $26 \%$ and for L50D6-10\% was $36 \%$ when compare with control specimen.

It was observed that tyre fiber modified concrete has shown good performance than the control specimen. Table 6 show that there was great increase in the impact resistance of the rubberized concrete with L50 10\% tyre specimen. It shows that tyre fibres in rubberized concrete are absorbing a lot of energy due to sudden impacts. They are not brittle like control specimen. They behave just like a ductile material.

\section{CONCLUSION}

From the above analysis the following conclusions were arrived.

The increase in the percentage of tyre fibers in the rubberized concrete reduces considerably the strength of concrete when compared with conventional concrete specimen. The length of the fiber, the diamenter of holes in the fiber also play a major role in the strength of tyre fibre modified concrete.

From Table 2 and 4, it is seen that for compression test on water absorbed cubes, L50D5-10\% mixed concrete shows good results than other specimens. L25 mix also shows good performance but it is due to most of the loads were taken by the concrete.

From Table 1 and 3, the compression test on acid absorbed specimen again rubberized concrete with L50D5-10\% mix shows good results when compared with other specimens.

From the above experiments it is clear that rubberized concrete with L50-D5 10\% has shown good transport characteristics.

From the Table 5 and 6 it is observed that the tyre fibre modified concrete behave as a ductile material while, the control specimen (with $0 \%$ tyres) behave as a brittle material. Also, the reduction in Ultimate Load with control specimen for L50-D5-10\% was only $11.8 \%$. This property may be considered as a milestone in the design of structural components, where the failure is of dutile nature, so that sudden collapse may be averted. It may be used in runway pavement where a lot of impact force is developed during the time of landing and takeoff. It is also 
Am. J. Engg. \& Applied Sci., 4 (3): 400-404, 2011

suitable for harbours where storage of containers has high impact always developing cracks on the floors and also suitable as a basement floor to withstand the high vibrations from the machines.

\section{REFERENCES}

Biel, T.D. and H. Lee, 1994. Use of recycled tire rubbers in concrete. Proceedins of the 3rd Materials Engineering Conference, Nov. 13-16, San Diego, CA, USA., pp: 351-358.

Bignozzi, M.C., A. Saccani and F. Sandrolini, 2000. New polymer mortars containing polymeric wastes. Part 1. Microstructure and mechanical properties. Composites Part A: Applied Sci. Manufact., 31: 97-106. DOI: 10.1016/S1359835X(99)00063-9

Dhir, R.K., M.C. Limbachiya, K.A. Paine, 2001. Recycling and reuse of used tyres. Proceedings of the International Symposium Organised by the Concrete Technology Unit, Mar. 19-20, Kingston University, London. http://eprints.kingston.ac.uk

Eldin, N.N. and A.B. Senouci, 1993a. Observations on rubberized concrete behavior. Cement Concrete, Aggregates, 15: 74-84.

Eldin, N.N. and A.B. Senouci, 1993b. Rubber-tire particles as concrete aggregate. J. Mater. Civ. Eng., 5: 478-496. DOI: 10.1061/(ASCE)08991561(1993)5:4(478)

Lee, B.I., L. Burnett, T. Miller, B. Postage and J. Cuneo, 1993. Tyre rubber/cement matrix composites. J. Mater. Sci. Lett., 12: 967-968. DOI: 10.1007/BF00420187

Li, Z., F. Li and J.S.L. Li, 1998. Properties of concrete incorporating rubber tyre particles. Mag. Concrete, Res., 50: 297-304. DOI: 10.1680/Macr.1998.50.4.297
Raghavan, D., 2000. Study of rubber-filled cementitious composites. J. Applied Polymer, Sci., 77: $\quad 934-942 . \quad$ DOI: $\quad 10.1002 /($ SICI)10974628(20000725)77:4<934::AID-APP30>3.0.CO;2$\mathrm{L}$

Raghavan, D., H. Huynh and C.F. Ferraris, 1998. Workability, mechanical properties and chemical stability of a recycled tyre rubber-filled cementitious composite. J. Mater. Sci., 33: 17451752. DOI: $10.1023 / A: 1004372414475$

Schimizze, R.R., J.K. Nelson, S.N. Amirkhanian and J.A. Murden, 1994. Use of waste rubber in lightduty concrete pavements. Proceedings of the 3rd Engineering Conference Infrastructure, Nov. 1316, San Diego, CA, USA., pp: 367-374.

Senthilkumaran, G.S., N. Mushule and M. Lakshmipathy, 2008. A review on construction technologies that enables environmental protection: Rubberized concrete. Am. J. Eng. Applied Sci., 1: 40-44. DOI: 10.3844/ajeassp.2008.40.44

Serge, N. and I. Joekes, 2000. Use of tire rubber particles as addition to cement paste. Cement Concrete, Res., 30: 1421-1425. DOI: 10.1016/S0008-8846(00)00373-2

Topcu, I.B., 1995. The Properties of rubberized concretes. Cem. Concrete Res., 25: 304-310. DOI: 10.1016/0008-8846(95)00014-3

Toutanji, H.A., 1996. The use of rubber tire particles in concrete to replace mineral aggregates. Cement Concrete Compo, 18: 135-139. DOI: 10.1016/0958-9465(95)00010-0

Wang, Y., H.C. Wu and V.C. Li, 2000. Concrete reinforcement with recycled fibers. J. Mater., Civ. Eng., 12: 314-319. DOI: 10.1061/(ASCE)08991561(2000)12:4(314)

Zheng, L., X.S. Huo and Y. Yuan, 2008. Strength, modulus of elasticity and brittleness index of rubberized concrete. J. Mater. Civ. Eng., 20: 692$699 . \quad$ DOI: $10.1061 /($ ASCE)08991561(2008)20:11(692) 